Малюков С.В., Аксенов А.А., Малюкова М.А.

Федеральное государственное бюджетное образовательное учреждение высшего образования «Воронежский государственный лесотехнический

университет имени Г.Ф. Морозова»

E-mail: malyukovsergey@yandex.ru

Аннотация: Мульчеры очень полезны при создании и уходе за лесом. Широкий спектр различных видов мульчеров может дезориентировать потенциальных покупателей. Данная статья была направлена на создание классификации мульчеров на основе оценки важнейших параметров: веса, требуемой мощности двигателя и диаметра срезаемой древесины. Были созданы шесть классов машин, определили их границы и назначили мульчеры для этих классов. Класс К1 (вес до 1300 кг; производительность до 75 киловатт; диаметр рабочего органа до 22 сантиметров) наиболее распространенный - 88 единиц мульчеров. За ним идет класс К2 (1800 килограммов; 100 киловатт; 27 сантиметров) - 61 шт., класса К4 (3200 кг; 175 кВт; 41 сантиметр) - 44 шт., класс К3 (2300 кг; 125 киловатт; 31 сантиметр) - 34 шт., класс К5 (4100 кг; 225 кВт; 51 сантиметр) - 18 шт. и класс К6 (без верхнего предела) - 9 шт.

Ключевые слова: мульчеры, диаметр срезаемой древесины, мощность двигателя, вес, классификация.

\title{
CLASSIFICATION OF MULCHERS
}

Malyukov S.V., Aksenov A.A., Malyukova M.A.

Federal State Budget Educational Institution of Higher Education «Voronezh State University of Forestry and Technologies named after G.F. Morozov»

E-mail: malyukovsergey@yandex.ru

Summary: Mulchers are very useful in creating and caring for the forest. A wide range of different types of mulchers can disorient potential buyers. This article was aimed at creating a classification of mulchers based on an assessment of the most important parameters: weight, required engine power and diameter of the cut wood. Six classes of machines were created, their boundaries were defined and mulchers were assigned to these classes. Class K1 (weight up to $1300 \mathrm{~kg}$; capacity up to $75 \mathrm{kil}$ - 
owatts; diameter of the working body up to 22 centimeters) the most common -88 units of mulchers. It is followed by class K2 (1800 kilograms; 100 kilowatts; 27 centimeters) - 61 pieces, class $\mathrm{K} 4$ (3200 kg; $175 \mathrm{~kW} ; 41$ centimeters $)-44$ pieces, class K3 (2300 kg; 125 kilowatts; 31 centimeters) - 34 pcs., class K5 (4100 kg; $225 \mathrm{~kW}$; 51 centimeters) - 18 pcs. and class K6 (without upper limit) - 9 pcs.

Keywords: mulchers, diameter of cut wood, engine power, weight, classification.

\section{Введение.}

Производители машинного оборудования имеют широкий ассортимент продукции для удовлетворения конкретных потребностей своих клиентов. В них используются новейшие научные знания в области дизайна, технологий, материалов и других областей исследований, чтобы не отставать от конкурентов. Однако они не могут удовлетворить потребности каждого потенциального клиента, так как теоретически это может привести к производству практически бесконечного количества типов машин, что значительно увеличит производственные затраты. Авторы $[9,13]$ описали процесс выбора машины, которые могут применяться в различных условиях. По их мнению, одним из самых важных факторов в инновационной продукции и улучшении экономики производства является оптимизация номенклатуры изделий, отраженной в конечном числе классов машин. Это позволяет производителям применять унификацию в дизайне, способствует экономической эффективности и повышает удовлетворенность клиентов. Производителям необходимо знать, какие машины (или классы машин) являются наиболее востребованными на рынке, чтобы иметь возможность эффективно фокусировать свои ресурсы.

Исследователи $[1,15]$ сосредоточились на классификации лесных машин. Они разработали свои системы классификации для разных видов машин, однако и их классификации не полностью применимы к лесным мульчерам. Они подошли к классификации лесозаготовительных машин и механизмов только через оценку двух переменных (производительности и веса). Они не учитывали совместное воздействие технических (например, вес машины) и эксплуатационных (например, требуемая мощность двигателя машины, диаметр срезаемого дерева, и т.д.) параметров. Кроме того, они разработали свою систему классификации для машинного оборудования, используемой при заготовке леса. В данной статье мы постарались рассмотреть как технические, так и эксплуатационные параметры одновременно, поскольку считаем, что данные машины, таким образом, дают ценную 
информацию, как потребителям, так и производителям.

Рао [11] описал возможности использования математической обработки данных при создании моделей, например, классификаций. Его работа дает ценную информацию о том, какой статистический анализ следует использовать. Лесные мульчеры и их характеристики привлекли внимание Эйзенбарта [3], который определил наиболее важные параметры для качества их работы. Он исследовал работу двух мульчеров во время расчистки лесных площадей. На основе измерений он определил, что производительность, затраты и техника больше всего влияют на качество работы мульчера. Земанек и др. [16] оценили инновационность машин на основе их технико-экономических параметров.

Авторы $[2,8]$ отнесли процесс мульчирования к числу энергетически затратных работ. Энергоемкость мульчирования или измельчения древесного материала зависит от вида срезаемой древесины, параметров резания (масса, производительность, скорость резания и т.д.), а также от формы и состояния режущего инструмента $[6,7,10,14]$.

Мульчеры - это универсальные машины. Широкий ассортимент их форм и размеров подтверждает этот факт. В данной статье представлена классификации мульчеров с механическим приводом по их основным технические и эксплуатационные параметры - требуемая производительность базовой машины, диаметр срезаемых деревьев и вес мульчера.

Материалы и методы. Предлагаемая классификация мульчеров с механическими приводами основана на методе, описанном [1]. Метод был изменен с учетом потребности этого исследования. Чтобы разработать классификацию мульчеров, создана база данных мульчеров с механическими приводами, проведен статистический анализ и разработаны критерии разделения мульчеров на классы.

Обширная база данных (статистическая выборка) мульчеров с механическим приводом, производимых во всем мире, была создана в соответствии с методом, описанным [5]. Каждая запись в базе данных содержала информацию о производителе, модели мульчера, весе, мощности трактора, частоте вращения вала отбора мощности и максимальном диаметре срезаемой древесины.

Дисперсионный анализ был использован для доказательства того, оказывает ли требуемая производительность существенное влияние на вес и диаметр срезаемой древесины. Взаимосвязь между требуемой производительностью и весом, а также между требуемой производительностью и диаметром срезаемой древесины была дополнительно изучена с помощью регрессионного и корреляционного ана- 
лиза. Отдельные мульчеры были разделены на группы и категории с помощью частотного анализа, то есть выявления и характеристики распределения численности машин с точки зрения производительности, веса и среднего размеров.

Мульчеры были разделены на группы по следующим критериям: (I) вес мульчера; (II) диаметр срезаемой древесины; (III) требуемая производительность, предусмотренная производителями мульчеров.

Производители мульчеров заявили о необходимой деления производительности на четыре части. Если они указывали верхний и нижний пределы производительности, в этом случае, среднее значение производительности рассчитывалось теоретически. Если производители предоставляли требуемую производительность как одно значение, то это значение было использовано для отнесения мульчера к соответствующей группе. Если производители предоставляли минимально требуемую производительность, число умножалось на коэффициент 1,2 и затем, мульчер заносился в соответствующую группу. Если производители предоставляли максимально требуемую производительность, число умножалось на коэффициент 0,8 и затем, мульчер заносился в соответствующую группу.

Была установлена длина интервалов классов для требуемой производительности [12], и группы были разделены на классы от К1 до К6. Каждый класс состоял максимально из трех групп и содержал как можно больше мульчеров.

Результаты и обсуждение. В таблице 1 показана техническая характеристика мульчеров с механическими приводами от 15 различных производителей.

Данные были разделены по соотношению между весом и требуемой производительностью и соотношение между диаметром срезаемой древесины и требуемой производительностью. Увеличение требуемой производительности на десять киловатт привело увеличению веса на 190 кг. Большинство мульчеров находились в требуемом диапазоне производительности от 50 до 150 кВт и весили от 500 до 2200 кг.

Мульчеры были разделены на группы в зависимости от их параметров (табл. 2). Группы были разделены на шесть классов от К1 до К6. Класс К1 содержал группы I и II, K2 - группу III, K3 - группу IV, K4 - группы V и VI, K5 содержал группы VII и VIII, а K6 содержал группы IX и X.

В таблице 3 показана популяция каждого класса. Классы от К1 до К4 наиболее актуальны для производителей. Мульчеры класса К1 чаще всего применяются на практике. Классы К5 и К6 содержат высокопроизводительные мульчеры с более низкими объемами работы. Мульчеры данных классов производятся исключитель- 
но по заказу и их технические параметры оптимизированы под требования конкретных потребителей. В таблице 4 приведены характеристики каждого класса.

Таблица 1 - Техническая характеристика мульчеров с механическими приводами

\begin{tabular}{|c|c|c|c|c|c|}
\hline Производитель & Модель & Вес, кг & $\begin{array}{c}\text { Мощность } \\
\text { трактора, } \\
\text { кВт. }\end{array}$ & $\begin{array}{c}\text { Частота } \\
\text { вращения } \\
\text { ВОМ, } \\
\text { об./мин. }\end{array}$ & $\begin{array}{c}\text { Макс. диаметр из- } \\
\text { мельчаемой расти- } \\
\text { тельности, мм }\end{array}$ \\
\hline FAE & UML / SS 150 & 970 & $45-82$ & $540 / 1000$ & 200 \\
FERRI & MC 180 & 545 & $41-52$ & 540 & 60 \\
AHWI & M700 & 4500 & $185-300$ & 1000 & 600 \\
SERRAT & FX3 & 631 & $32-44$ & 540 & 30 \\
MERI & MJS-2.0 DT & 1610 & $82-135$ & 1000 & 250 \\
FAE & UMH 175 & 2910 & $97-112$ & 1000 & 400 \\
SERRAT & FX5 T-2000 & 2470 & $110-150$ & 1000 & 200 \\
VENTURA & TFVJ 130 & 625 & min 30 & 540 & 180 \\
TEAGLE & EKR / S250 & 645 & $45-60$ & $540 / 1000$ & 30 \\
OSMA & TLPF 220 & 1290 & $89-104$ & 1000 & 250 \\
FAE & SSH 225 & 4581 & $164-261$ & 1000 & 690 \\
FECON & BH200 & 2449 & $104-336$ & 1000 & 500 \\
SEPPI M & FORST M & 4900 & 125 & 1000 & 300 \\
RYETEC & TRB 180 & 1220 & $60-82$ & 1000 & 150 \\
BUGNOT & BFO 1800 & 2560 & max186 & 1000 & 500 \\
\hline
\end{tabular}

Таблица 2 - Количество мульчеров, отнесенных к отдельным группам

\begin{tabular}{|c|c|c|c|c|c|c|c|c|c|c|}
\hline Группа & I & II & III & IV & V & VI & VII & VIII & IX & X \\
\hline $\begin{array}{c}\text { Количество } \\
\text { мульчеров, } \\
\text { шт. }\end{array}$ & 13 & 75 & 61 & 34 & 18 & 26 & 8 & 10 & 7 & 2 \\
\hline
\end{tabular}

Таблица 3 - Количество мульчеров, отнесенных к отдельным классам

\begin{tabular}{|c|c|c|c|c|c|c|}
\hline Класс & К1 & К2 & К3 & К4 & К5 & К6 \\
\hline $\begin{array}{c}\text { Количество } \\
\text { мульчеров, шт. }\end{array}$ & 88 & 61 & 34 & 44 & 18 & 9 \\
\hline
\end{tabular}

Таблица 4 - Спецификация нижнего и верхнего пределов класса для требуемых характеристик двигателя, веса и диаметра срезаемой древесины мульчеров с механическими приводами

\begin{tabular}{|c|c|c|c|c|c|c|}
\hline Параметр & К1 & К2 & К3 & К4 & К5 & К6 \\
\hline $\begin{array}{c}\text { Производительность } \\
\text { двигателя (кВт·ч })\end{array}$ & $0-75$ & $76-100$ & $101-125$ & $126-175$ & $176-225$ & $\begin{array}{c}\text { более } \\
225 \\
\text { более } \\
4100 \\
\text { Вес, кг }\end{array}$ \\
$\begin{array}{c}\text { Диаметр срезаемой } \\
\text { древесины, мм }\end{array}$ & $0-1300$ & $1400-1800$ & $1900-2300$ & $2400-3200$ & $3300-4100$ & $\begin{array}{c}\text { более } \\
510\end{array}$ \\
\hline
\end{tabular}


Классификация машин, основанная на более чем двух параметрах, широко распространена на практике. Эйзенбарт [3] утверждал, что производительность, цена и техника больше всего влияют на качество подготовки местности. Данная информация подтверждает выбранные нами параметры для предложенной классификации - производительность мульчера (определяется диаметром срезаемой древесины) и вес (качество и количество материала, используемого на протяжении всего производства машины, влияет на ее цену). Авторы статьи [16] оценивали инновационность машин на основе их технико-экономических параметров. Они также учитывали технологический процесс при выборе соответствующих машин. Включение экономических параметров мульчеров в классификацию проблематично, поскольку цена не является фиксированной величиной и зависит от времени покупки и комплектующих мульчеров. Эксплуатационные экономические параметры мульчеров, такие как переменные затраты, также изменяются в зависимости от условий, в которых они работают (например, рельеф местности, базовая машина, обрабатываемый материал, природные условия, в которых используются мульчеры и т.д.).

\section{Выводы.}

Эта классификация отражает потребности лесного хозяйства на практике. Она может служить руководством для производителей машин, когда они оптимизируют свой ассортимент продукции. Удовлетворение рыночного спроса минимальными видами продукции особенно важно для экономики машинного производства и унификации деталей машин. После распределения мульчеров по классам можно увидеть популярность каждого класса. Это выгодно производителям мульчеров, так как они будут иметь ценную информацию о состоянии рынка и своих конкурентах. Эта категоризация отражает технические характеристики заказчика (лесхоза) после деления этих размерных типов и может быть для производителей машин поддержкой в определении оптимальной конструкции фрезерных рабочих органов. Удовлетворение рыночного спроса при минимальном количестве типов особенно важно для производителя в экономическом плане и с учетом унификации конструкции. Они могут принять обоснованное решение о том, какие типы мульчеров производить. Предложенная классификация также может улучшить процесс принятия решений потребителями. Они будут одновременно получать информацию о том, какой мульчер они могут установить на базовые машины, которыми они уже владеют, и будет ли он достаточно мощным для их предполагаемых целей.

\section{СПИСОК ЛИТЕРАТУРЫ}

1 Bukoveczky, J., Gulan, L., Zajacová, L. \& Schmidtová, C. Určenie vel'kostného radu skupiny mobilných pracovných strojov (Determination of size range of mobile 
machines) // Zborník MVK Mobilné energetické prostriedky -Hydraulika - Životné prostredie - Ergonómia mobilných strojov, FEVT, Zvolen 2007.

2 Čedík, J., Pexa, M., Chyba, J., Vondrášek, Z. \& Pražan,R. Influence of blade shape on mulcher blade air resistance // Agronomy Research, 2016, no. 14(2), pp. 337-344.

3 Eisenbarth, E. Mulchgerate im Praxisvergleich (A comparison of mulching machines) // AFZ/Der Wald 55, 2000, pp. 518-522.

4 Gitlow, H. Tools and Methods for the Improvement of Quality. Richard D. Irwin, INC., Homewood, Illinois, 1989, 603 p.

5 Hnilica, R., Mesingerová, V., Hnilicová, M. \& Stanovský,M. Drviče nežiadúcich nárastov s mechanickým prenosom energie (Mulchers of undesirable advance growth with mechanical transmission of energy). // Les. Pr. 92, 2012, pp. 152-158.

6 Hosseini, S. S. \& Shamsi, M. Performance optimization of a rotary mower using Taguchi method. // Agronomy Research, 2012, no. 10(1), pp. 49-54.

7 Kronbergs, A., Kronbergs, E. \& Repsa, E. Evaluation of reed canary grass shredding and compacting properties // Agronomy research, 2013, no. 11(1), pp. 61-66.

8 Kumhála,F., Chyba, J., Pexa, M. \& Čedík,J. Measurement of mulcher power input in relation to yield. // Agronomy Research, 2016, no. 14(4), pp. 1380-1385.

9 Majdan, R., Tkáč, Z., Abrahám,R. \& Kosiba, J. Teória a konštrukcia traktorov (Theory and construction of tractors) Slovak University of Agriculture in Nitra, Nitra Slovakia, 2012, 100 p.

10 Pecenka, R. \& Hoffmann, T. Harvest technology for short rotation coppices and costs of harvest, transport and storage // Agronomy Research 2015, no. 13(2), pp. 361-371.

11 Rao, S. Reliability-Based Design. McGraw Hill, New York, 1992, 569 p.

12 Scheer, L. \& Sedmák,R. Biometria (Biometry). Technická univerzita vo Zvolene, Zvolen, Slovakia, 2007, 333 p.

13 Sloboda, A., et all. Konštrukcia kolesových a pásových vozidiel: teória, konštrukcia, riziká. (The design of wheeled and crawler-type vehicles). Vienala, Košice, 2008, 547 p.

14 Syrový,O., et all. Energy savings in crop production technologies. In : Research Institute of Agricultural Engineering, p. r. i., Prague, 2008, 101 p.

15 Štollmann, V. \& Slugeň, J. Návrh novej kategorizácie harvesterov na základe analýzy hmotnostných a výkonových parametrov (A proposal of new classification of harvesters based on weight and performance parameters). // Acta Facult. For. 2009, no.51, pp. 101-109.

16 Zemánek, P., Abrham, Z. \& Burg, P. Economic effectiveness of mulching machines operations. // Hortic. Sci., 2004, no. 31, pp. 76-80. 